\section{THE BIRTH OF CHEMISTRY}

$$
\text { I. }
$$

\section{In'roduction-Ancient Science-Origin of Chemistry-Derivation of the Name-Definitions of Chemical Science-Early Ideas relative to the Formation of the World.}

THE history of a natural science resembles in many respects the history of a nation. In each instance the object is first to obtain a knowledge of causes, then to frame laws. The first are those causes which most promote the well-being of the nation, the second those causes which produce the phenomena of the Universe. In each instance we start with an absence of all law, and we may observe the slow efforts of the human mind to trace each effect to its proper cause, to group together causes, and finally to connect them by one bond. The main difference is this, that in the case of the nation man has to deal with laws which must be founded upon a just study and close observance of every phase of that particular community, influenced as it is by numberless external causes, such as race, climate, religion, habit of thought, tradition; while in the case of the science he has to evolve pre-existent laws, also by the close observance of facts, which are hidden from him by the complex mechanism of nature. M. Taine would tell us that the laws which influence the development of peoples are just as absolute, definite, and pre-existent, as those which govern the affairs of nature; but we are quite disinclined to admit this, even in regard to one particular race, in one particular locality. In both histories we have similar forms of government, similar assemblies of lawgivers; we have our aristocracies, oligarchies, democracies, republics: we have at some period or other Conservatives and Liberals of every shade. We know not what Conservative rule can compare with the dominance of the science of Aristotle for twenty centuries, and we cannot be too ready to welcome the Liberal-conservative era of. Copernicus and Giordano Bruno, the Liberal era commenced by Galileo and Francis Bacon, which by easy stages is passing, if it has not passed, into the right Radical era of modern scientific thought. The "Republic of Learning" is no empty phrase.

No one would venture to deny the value of a knowledge of the history of nations, and we are inclined to believe that the history of the natural sciences is not without its uses. It is neglected because during the last century new discoveries have quickly succeeded each other, old sciences have augmented, while new sciences bave arisen ; in fact, the progress of science has been so extraordinarily rapid that we have scarcely time to turn aside and look at its past history; the present is sufficient for us, and if we once get out of the main current of thought we have difficulty in regaining lost ground. Yet we may no more forget that we owe our present wise laws and great constitutional system to the labours of ten centuries of men, than that our science of to-day represents the accumulation of the scientific thought of twice ten centuries. Intellectual revolutions have not been less frequent than social revolutions, nor battles of the pen than battles of the sword; the crash of a fallen philosophy has often been louder than that of a fallen throne; the wail of the last Phlogistians rent the heavens; the Aristotelian physics died with groanings and gaspings and a discoloured visage.

In tracing the history of a science, we are first led to inquire whether the Ancients possessed any knowledge of it, and whether it originated among them. Now the Ancients made but little progress in any of the natural sciences. They divided all human knowledge into three parts : Logic, or mental philosophy; Physics, or natural philcsophy Ethics, or moral philosophy. Some placed loyic first, some ethics. but no one physics. Philosophy was compared to an egg-logic the shell, physics the white, ethics the yolk; or, again, it was compared to a living creature-logic the bones, physics the flesh, ethics the soul. Plato separates logic as the knowledge of the immutable, from physics the knowledge of the mutable. The Cynics sought a complete freedom from any object or aim in life, and renounced all science. Sokrates aimed at logical definition, and affirmed that the true nature of external objects can be discovered by thought without observation. The knowledge of one's self $\left(\gamma \nu \hat{\omega} \theta_{\imath} \sigma \epsilon \alpha \nu \tau \delta \nu\right)$ is the true object and aim of all philosophy. Knowledge obtained from external sources is worthless ; there is nothing to be learned from fields and trees. A certain philosopher is said on this principle to have put his eyes out, in order that his mind might not be influenced by external objects, and might be left to pure contemplation. (How curiously this contrasts with the plaint of Galileo just before his death, "Prot dolor! the sight of my right eye, that eye whose labours, I dare say it, have had such glorious results, is for ever lost. That of the left, which was and is imperfect, is rendered null by a continual weeping.") Others of the ancients allowed that geometry might be employed for the measurement of land, and astronomy cultivated so far as it might be of use to sailors, but on no account as serious subjects of mental occupation.

Thus it happened that natural science made but little progress among the ancients ; thus it happens that a schoolboy of twelve knows more about earth, and fire, and water, than was dreamt of in the philosophies of the greatest thinkers of antiquity. Let us, however, give them their due; let us confess that Plato possessed the "finest of human intellects, exercising boundless dominion over the finest of human languages ;" that Aristotle was the greatest genius the world has ever seen; that as pure intellectual evolutions they have handed down to us a mass of grand philosophy; ten thousand noble efforts of the human spirit. Everything favoured the exercise of the unaided intellect, while it is hard to estimate the difficulties which presented themselves in the investigation of nature. At one period it was considered impious to attempt to explain the manifestations of the gods. There was an outcry in Athens, a popular demonstration, when the thunderbolts of Zeus were referred to common fire produced by the collision of clouds. The feeling was of the same nature as that conveyed by Campbell's stanza:-

When Science from Creation's face

Enchantment's veil vithdraws

What lovely visions yield their place

To cold material laws!

only the feeling existed in an intensified form, for here the first of the gods was derirled-the Olympian Zeus, Lord of the Air, he who rides upon the storm, and huris the thunderbolt. For a length of time, therefore, any investigation of nature was impossible for religions reasons. Men were to worship nature, to be filled with awe and wonder- $\delta \epsilon เ \sigma\left\llcorner\delta u \iota \mu \nu v^{\prime} a-\right.$ in presence of great natural phenomena, but not to incuire too closely into their causes. Twenty centuries later the Doctrers of Salamanca who interrogated Columbus, the Inquisitors of the Sacred College who examined Galileo, upheld the same old doctrines, albeit the old gods had passed away. But the investigation of nature was impossible among the Greeks; their capabilities were very limited, they had no instruments for observations or experiments of any kind, neither had they the faculty of observation; their minds were untutored in that particular direction. Then they had to contend against their own particular habit of thought, the extreme tendency to concretion, to hasty generalisation from purely mental premiszes; or if an observation bad been made, a broad general law was deduced from it without further observation. So also the Chaldreans and Parsis had to contend against the mysticism, the astrology, and magic, which originated among them ; and the ancient Hindu was su given to extreme abstrac tion, and to the evolution of all manner of strange metaphysical dogmas, that we could scarcely look for much science from an Eastern source. Egyptian learning was monopolised by the priests, and they so wove together the real and the unreal, and were so secret withal in their actions, that although much of the Greek learning came direct from Egypt, we cannot trace it to its direct source, or point to one Egyptian writer on philosophy. The Greeks, too, received much from the Phonicians; but here also we find no record. We will presently inquire more fully into the exact amount of science possessed by the ancients.

We have chosen for our historical survey one of the oldest of the natural sciences, for obvious reasons, the chief being that it will enable us to observe more minutely the early thoughts of ancient peoples in regard to certain phenomena of nature. The science of chemistay does not owe its existence to any one people, or $t_{i}$ any sudden process of development. The basis of the edifice is sunk deep in Eastern soil ; the time when the foundation store was laid is too remote to be even suggested; the walls were slowly and laboriously raised during the Middle Ages, and were completed by Lavoisier, Black, and Priestley; the men of our day are working at the roof. We neither hold with M. Goguet that Moses possessed considerable knowledge of chemistry, because he dissolved the golden calf, nor with M. Wurtz, when he says "La chimie est une science Française. Elle fut instituée par Lavoisier d'immortelle mémoire." Chemistry was not a science until long aíter the time of Moses; it was a science long before the time of Lavoisier. We wonder what Dr. Hermann Boerhaave of Leyden (whose large quarto "Elementa Chemix" was published in 1732 , nine years before the birth of Lavoisier), would say to the proposition of M. Wurtz. Short of 
this, it would be difficult to overrate the services which Lxvoisier rendered to chemistry. But the science has grown up by a gradual process of evolution ; upon its surface we find the impress of many and diverse phases of thought and of action; the science of to-day is the summation of many intellectual efforts produced by the constant struggle of the human mind for truth. How often that truth has been hidden by a mass of sophistries; how often it has been absorbed by some false philosophy to appear again untarnished in due time; how often the attempt has been made to crush it under foot; and how it has ever risen to the surface at last, all who read the history of faiths, nations, ideas, must know. It will be our object to show this is the study of the particular science which now engages our attention.

The word $\chi \eta \mu \in i a$ first occurs in the Lexicon of Suidas, a Greek writer of the eleventh century; he defines it as "the preparation of gold and silver." In the "Lexicon GræcoLatinum" of Robertus Constantinus, published in 1592, the same definition is given, and Suidas is quoted as the authority. According to Olaus Borrichius, however, there were Greek writers on alchemy before this date; there is said to be a Greek MS. of the fifth century on alchemy in the King's Library in Paris, and others of a somewhat later date in the libraries of Munich, Milan, Venice, Hamburg, and Madrid; but we are inclined to doubt whether any of these were written before the ninth or tenth century. They are probably the work of monks living at Alexandria and Constantinople ; indeed, one of them is entitled, "Cosma the Monk, his Interpretation of the Art of making Gold." The titles of some of the others will prove to us that we can place but little faith on any date which may be assigned to them :-

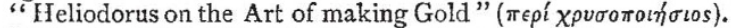
Art."

"John the High Priest, in the Holy City, concerning the Holy

"Isis the Prophetess to her son Orus."

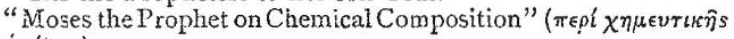

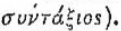

"Cleopatra on the Art of making Gold."

"Democritus the Abderite, the Natural Philosopher, on the Tincture of Gold and Silver, and on Precious Stones and Purple."

Equally worthless, we believe, are the Greek derivations of the word chemistry. Many (among others M. Hoefer) derive the word from $\chi^{\prime} \omega$, to fuse or melt, because the majority of old chemical operations were effected by fire--witness calcination, ignition, distillation, sublimation, desiccation, reverberation. The earliest chemical arts, such as the smelting of metals and the production of glass, were also operations of fire. Indeed, the science has been called Pyrotechnia ( $\pi \hat{\imath} \rho$ $\tau \chi^{\prime} \chi^{\nu \eta}$, the art of fire), because, says Lemery, in his "Cours de Chimie," "we in effect produce all chemical operations by means of fire." Others derive chemistry from $\chi \hat{v} \mu \alpha$-that which is poured out, a liquid, in allusion to the various liquids used in chemical operations but this derivation is not worth a moment's notise. We must rather look to an Egyptian source. Plutarch tells us that Egypt was called Chemia, on account of the black colour of the soil, and that the same term was applied to the black of the eye which symbolises that which is obscure and hidden. This word is related to the Coptic khems or chems, which also signifies obscure, occult, and is connected with the Arabic chema, to hide. It is probable that we have here the true derivation of the word chemistry. The first treatise on the science, the date of which is known with any certainty, was written by the Arabian Yeber or Geber, and at that time (the eighth century), Arabic learning had considerable influence on European culture. The science was called the occult, or hidder, because it related principally to the secret art of the transmutation of metals, as the definition of Suidas, given above, and the earlier works on the science prove. The term black art has been applied both to alchemy and to the magical arts so often associated with it, and clearly agrees with the above derivation. The $a l$ in alchemy is the Arabic particle the, so that alchemy signifies "the hidden science" par excellence; we notice the same prefix in alkoran, alcohol (the burning liquid), alkali (the acrid substance), algebra, alembic (the cupshaped vessel), and in the names of many stars, as Aldebaran, Algenib, Alpheratz,- - all words of Arabic origin.

fy Whatever difficulties there may be in determining the precise derivation of the word chemistry, there can be none in defining the science as distinctly and definitely the science which treats of the changes which matterundergoes; while physics proper treats of the action of varioits forces - heat, light, electricity, magnetismupon matter, in all cases unaccompanied by any change of composition. If we heat a piece of iron to redness, or cause it to convey an electric current, or place it in contact with a magnet, it has been submitted to various actions, but when they are re. moved it returns to its original condition. On the contrary, if we fuse it with sulphur a chemical change takes place, a new substance is formed, and the iron does not return to its original condition. This idea of change is the fundamental chemical conception. The first man who made glass, or extracted a metal from its ore, effected a chemical change; the idea became most sovereign and dominant in alchemy, the attempt to change base metals into gold ; it reigned throughout the period of phlogistic chemistry, for was not phlogiston a subtle entity which effected changes in matter according as it was assimilated by matter or rejected from it? It is equally the character of the chemistry of Lavoisier and Cavendish, of Davy and Dalton, of Bertholet and Cannizzaro. The "philosopher's stone" (of which much more anon) was a substance supposed to chanoe all things into gold; the "elixir vita" was a substance which was to change old men into youths; the "universal solvent" was to change everything to a liquid form. Let us look at some of the definitions of chemistry. Boerhaave says, "Chemistry is an art which teaches the manner of performing certain plyysical operations, whereby bodies cognizable to the senses, or capable of being rendered cognizable, and of being contained in vessels, are so changed by means of proper instruments, as to produce certain determined effects, and at the same time discover the causes thereof, for the service of various arts." Sir Humphrey Davy writes as follows:- "Most of the substances belonging to our globe are constantly undergoing alterations in sensible quantities, and one variety of matter becomes, as it were, transmuted into another. Such changes, whether natural or artificial, whether slowly or rapidly performed, are called chemical; thus the gradual and almost imperceptible decay of the leaves and branches of a fallen tree exposed to the atmosphere, and the rapid combustion of wood in our fires, are both chemical operations. The object of chemical philosophy is to ascertain the causes of all phenomena of this kind, and to discover the laws by which they are governecl." Quite recently Dr. Miller defined chemistry as "the science which teaches us the composition of bodies," and such knowledge we can only obtain by pulling matter to pieces (analysis), or by building it up (synthesis). Dr. Hofmann of Berlin has defined the vast body of so-called organic chemistry as "the history of the migrations of carbon," and is not migration change of place?

Chemistry, then, is the science which treat; of tie various kinds of matter, whether simple or compound, of which the world is composed, their properties, and the laws which govern their combination with, and separation from, each other. We shall first discuss any ideas of the ancients which bear upon changed matter in any form or condition: thus their early cos. moginies; the knowledge they possessed of metals and com. pound bodies; and their various technical operations, such as glass making and smelting, alike demand our attention.

If we compare all the earliest ideas as to the formation of the world, we find them resolve themselves into the belief that the ether and chaos, mind and matter, were the original principles of things. The ether, a subtle vivifying principle, "passing as a mighty breath over the chaos; the chaos a boundless watery expanse without form." It was thus according to S inchoniathon in the belief of the Phœnicians, and the twenty-five principles of the Hindu philosophy of San'chya are finally reduced to these-matter and spirit, nature and soul. The Egyptian deity was called Nûm as the spirit moving over the face of the waters, Pthah as the principle of production. The Hindu deity Brahme typified the productive force of nature. Among more western nations Gaia, the personification of earth, was held to be the first that sprung from Chaos, and the wife of Ouranos. Okeanos wa their so3, and according to Homar was the source of all the gods. The worship of the elements, and of the sun and moon, was among the very earliest forms of worship ; thus we have in India, Agni the god of fire, Indra the god of the firmament; the sun was sometimes worshipped as a symbol of the deity, sometimes as a deity ; fire was worshipped by the ancient Persians as a symbol of the deity; in the Homeric religion we find the Olympian Zeus, lord of the air, who possesses absolute and Universal power. We must notice, too, Aidoneus, the brother of Zeus, and lord of the Underworld, said by some of the Greek philosophers to designate earth, and undoubtedly an old nature 
power. Again, "Hephaistos," says Mr. Gladstone, "bears in Homer the double stamp of a nature power representing the element of fire, and of an anthropomorphic deity who is the god of art at a period when the only fine art known was in works of metal produced by the aid of fire." He is also one of the seven star-deities of Chaldia, the signs and names of which were given at an early date to the seven metals.

\section{G. F. RODWELX}

\section{THE AMERICANEXPLORING EXPEDITIONS *}

THE various Government exploring expeditions, the departure of which to the fields of operation for the season we have already announced, are busily engaged in carrying on the important work entrusted to them; and it will be safe to expect as the result a larger addition to our stock of detailed information respecting the western regions of America than has ever been brought together during a single year. The most important of these parties are the northwest boundary survey, the geological explorations of $\mathrm{Mr}$. Clarence King along the fortieth parallel, and the surveys of Lieutenant Wheeler in Nevada and Arizona, under the War Department ; that of Prof. Hayden, in two divisions, under the Interior Department ; and that of Major Powell in Colorado, under the Smithsonian Institution.

Perhaps the most thoroughly equipped and elaborate exploration is that of Lieutenant Wheeler, which is now fairly in the field, and engaged in carrying on its work. This has for its object a thorough investigation of the region west of the hundredth meridian, for the purpose of determining its geographical positions, thoroughly working out its topography, and investigating its geology, natural history, and climatology.

As the basis of this work, it is proposed by Lieutenant Wheeler to divide the region referred to into eighty-five rectangles of equal size, and to mark their comers with great precision, then, taking each one in detail, to determine its astronomical, physical, and natural history features. This, of course, will require considerable time for its completion; and it is hoped that Congress will grant the necessary authority, so that the work may be accomplished as speedily as possible. As each rectangle is elaborated, it will, of course, join on to those previously investigated; and an index map is to be carried along simultaneously for the more ready understanding of the details. Eight rectangles have been completed by Lieutenant Wheeler in his previous expeditions, and it is expected that thirteen will be finished by the end of the season.

To carry out this programme certain points are to be determined astronomically with great precision, and these as nearly as possible along a continuous parallel. Those already selected are, according to the Neiv York Herald, a point near Beaunois, near north-western Kansas ; the crossing of the Union Pacific and the western boundary of Nebraska; Cheyenne ; the eastern limit of the survey of the fortieth parallel by Clarence King; Sherman, the highest point on the. Union Pacific; Fort Steele ; Laramie City; the crossing of the Union Pacific and the western boundary of Wyoming; the crossing of the Central Pacific and the roth meridian ; and a point on the western boundary of Nevada.

Telegraphic determination of the longitude will be used very freely, and for this purpose Brigham Young has kindly permitted the employment of his well-equipped observatory in Great Salt Lake City. It is proposed to establish a principal station at or near Sherman, the position of which will be determined with the utmost accuracy, and to use this as a point of reference for the other stations referred to. The work of the present season will be carried on almost simultaneously in Utah, Arizona, and Nevada, several divisions of the main party having already been organised and set to work. The southern and south-western portions of the Salt Lake basin are to be explored; also the mining regions on the Virgin and in Eastern Nevada. It is proposed to establish astronomical points, by means of which to determine with greater accuracy the location of the mineral veins. The Wasatch Mountains will constitute the eastern limit of operations during the year.

The expedition, as organised, embraces the following among the more important of the personnel :-Lieut. George M. Wheeler, United States Engineers in command; Lieuts. R. L. Hoxie and W. L. Marshall, U. S. Engineers; Dr. H. C. Yarrow, surgeon and naturalist ; T. V. Brown, hospital steward and meteorologist ; G. K. Gilbert and E. E. Howell, geologists; J. H. Clark and
E. P. Austin, astronomical observers; Louis Nell and John E. Weyss, chief topographers; H. W. Henshaw, assistant natu ralist; M. S. Severance, ethnologist ; and William Bell, photographer.

At the latest advices the latitude and longitule of Beaver, in Utah, were being determined by Mr. Clark, Mr. Anstin being stationed at the Salt Lake City Observatory. Pioche, in Nevada, will be the next point to be occupied. One branch of the expedition, under Lieut. Hoxie, and accompanied by Dr. Yarrow as naturalist, is exploring the regions west of Great Salt Lake City while the other, under Lieutenant Wheeler, is survêying the Wasatch and the Sevier River "regions east of it. From these main divisions parties are sent out to examine the water-courses and mountain regions of the country traversed. They will all concentrate at Beaver, Utal, about October I, and proceed together toward the south.

\section{ITALIAN SPECTROSCOPY}

PROF. TACCHINI presented the matter for the fourth issue of the Giornale degli Spettroscopisti, consisting of two memoirs, one by Prof. Blaserna, on the displacement of the lines of the spectrum according to the heat of the prism; the other, by Prof. Donati, on observations of the spectra of solar spots made at Florence with a new spectroscope.

The new spectroscope of Prof. Donati contains twenty-five prisms. They are so arranged that the eye receives only Fraunhofer's line C, and a small portion of the red to the right and left of that line. With this spectroscope Donati has succeeded in seeing clearly the line $C$ reversed on the nucleus of the spots. It does not appear that any of the Italian observers have yet seen the prominences on the disc, a result announced by Lockyer in 1869 .

Prof. Tacchini further directed the attention of the Society to bis last spectroscopic observations of the sun. For the last few days the number of the protuberances had been rather small, but the chromosphere had been greatly developed, and the vapours of magnesium mixed with it had occupied regions of vast extent. He exhibited a drawing of the spectroscopic image of the Sun's edge, taken on the morning of the 6 th of May, 1872 , showing the continuous presence of magnesium over an arc of $168^{\circ}$, extending from the north pole to distances of $50^{\circ}$ and $118^{\circ}$. This was the first time that he had observed a mag. nesium region of such vast extent in the sun. And taking account also of isolated tracts, there results a total of $222^{\circ}$, that is to to say, nearly two-thirds of the entire edge, occupied by magnesium vapours more or less intense. The drawing likewise shows the usual correspondence between the faculæ, the magnesium regions, and the portions of the edge at which flames arise to the height of 14 to 28 seconds.

Lastly, Prof. Tacchini gave an account of some spectroscopic observations maae at Geneva by Prof. E. Gautier, and exhibited the drawings of a protuberance observed by Gautier on the $15^{\text {th }}$ of April of this year, which serve to confirm the observations made at Palermo on the solar rains, that is to say, masses of luminous hydrogen suspended in the sun's atmosphere, which gradually separate, and ultimately unite at the edge of the disc and then present all the appearance of exuption, whereas their formation actually takes place by a directly opposite process.

Prof. Blaserna said that he had heard with much interest of Donati's attempt to observe the reversal of the lines on the solar spots. He had also, in accordance with the admirable $\supset$ onferences of Prof. Tacchini in January last, occupied himself with the problem of observing the protuberances on the full solar disc. $\mathrm{He}$ then wrote to Prof. Tacchini a detailed letter, proposing two different methods of arriving, if possible, at the solution of this important problem.

The first of these methods, already applied by Janssen and Lockyer to the protuberances on the solar edge, and now adopted by all spectroscopists, consists in using spectroscopes of continually greater power. Prof. Donati has also pursued this method, and has now arrived at the construction of a spectroscope of twenty-five prisms. Theoretically, it is highly probable that in this manner the protuberances might ultimately be seen in full sunshine. But for this it would be necessary to go much further with the number of prisms, increasing them to 50,73 , or perhaps even to 100 . This, however, involves a great practical difficulty, and, moreover, it is doubtful whether so powerful a 